\title{
Factors Associated With Herbal Medicine Use in Pregnancy Among Postnatal Mothers in Mbarara Regional Referral Hospital in Western Uganda
}

Laban Muteebwa ( $\nabla$ mutlabans@gmail.com )

UVRI-IAVI HIV Vaccine Program

Ali Ssetaala

UVRI-IAVI HIV Vaccine Program

Dan Muramuzi

Mbarara National Referral Hospital

Annet Nanvubya

UVRI-IAVI HIV Vaccine Program

Yunia Mayanja

MRC/UVRI \& LSHTM Uganda Research Unit

Research Article

Keywords: Herbal Medicine, Postnatal Mothers, pregnancy

Posted Date: February 8th, 2021

DOl: https://doi.org/10.21203/rs.3.rs-141153/v1

License: (9) This work is licensed under a Creative Commons Attribution 4.0 International License.

Read Full License 


\section{Abstract}

\section{Background}

There is widespread use of herbal medicines among populations in sub-Saharan Africa. However, pregnant women should be conscious about medication taken during pregnancy including herbal medicines because their safety profiles are not known and some of them might affect the mother, fetus and pregnancy outcomes. Knowledge about use and safety of herbs in pregnant women is limited. This study aimed to assess the extent of use and the factors associated with use of herbal medicine in pregnancy.

\section{Methods}

A cross-sectional study involving 385 women 6 weeks post-partum and below, receiving post-natal services at Mbarara Regional Referral Hospital in Western Uganda was conducted during May to August 2016. Simple random sampling was used to select participants. A structured pretested questionnaire was administered after written informed consent. Data was analyzed using logistic regression (STATA- 14).

\section{Results}

Of 385 respondents, 70.4\% reported to have used herbal medicine during their most recent pregnancy. Associated factors were perception that herbal medicines are safe (aOR 9.8, 95\% $\mathrm{Cl}$ (4.2-23.0), perception that herbal medicines are important (aOR $12.4,95 \% \mathrm{Cl}(5.2-29.5)$, staying more than $10 \mathrm{KM}$ from the heath facility (aOR 3.1, 95\% Cl (1.4-6.9), being a first time mother (aOR 2.6, 95\% $\mathrm{Cl}(1.1-6.2)$ and dissatisfaction with ANC services at health facility (aOR $2.6,95 \% \mathrm{Cl}(1.1-6.3)$

\section{Conclusion}

Herbal medicine use in pregnancy is common in the study area. Community Sensitization drives about the dangers of herbal medicine use in pregnancy is recommended. Healthcare workers should routinely screen for herbal medicine use during antenatal care visits and labor.

\section{Background}

The use of traditional and complementary medicine has expanded globally and become increasingly popular(1). Herbal medicine is an integral part of traditional medicine in Uganda and other Low and middle income countries. Herbal medicines are defined as plant-derived materials and preparations perceived to have therapeutic benefits, containing raw or processed ingredients from one or more plants $(2,3)$. It is estimated that $80 \%$ of the rural population in developing countries depends on traditional medicine for their health needs, and this includes pregnant women(4). Pregnant women should be concerned about all medication taken during pregnancy including herbal medicines(5), because some of them might affect the mother, fetus leading to poor pregnancy outcomes. Most pregnant women believe that herbal medicines are 'natural' and 'safe' compared to conventional medicines(1). Moreover they are 
not subject to the same formal and strict regulation as conventional medicines in many countries $(6,7)$. World Health Organization (WHO) estimates that about $7-55 \%$ of pregnant women use herbal remedies during the course of pregnancy depending on the region and ethnicity (8). Additionally, a systematic review of publications in the Middle East reported a prevalence of herbal medicine use amongst pregnant women to be $22.3-82.3 \%(9)$.

In Africa, more pregnant women use herbal remedies to treat pregnancy related problems due to costeffectiveness of therapy and easy access of these products(1), regardless of the inadequate knowledge and evidence about their safety. Herbal medicine use during pregnancy, labor or the postpartum period occurs at rates ranging from $30-70 \%$ in a healthcare setting in urban areas of sub-Saharan Africa(1012).

In Uganda, the prevalence of herbal medicine use during pregnancy and delivery is reported to be $>80 \%$ in Western Uganda (13) and 20\% in Northern Uganda(14). Reports from the Health Management Information Systems (HMIS) in Uganda, indicate that in the year 2012/13, the still birth rate was $2.8 \%$, (15), and taking herbal medicines was cited as one of contributing factors. Moreover, Nelson et al (2016) detailed how maternal death in western Uganda occurred secondary to a posterior uterine rapture, associated with the herbs taken during labor (16). A study done at Mbarara regional referral hospital in 2013 found that $35 \%$ of the women who had uterine rapture had actually taken herbal preparations during labor process, and were 15 times more likely to get it than those who did not(17). It is also documented that pregnant mothers don't usually disclose use of these herbs to their attending health care workers $(9,11,18)$.

Despite the consequences of using herbal medicines, data on the magnitude and factors associated with herbal medicine use in pregnancy, are still limited. We determine the extent of use and factors associated with herbal medicine use in pregnancy among post-natal mothers in Mbarara Regional Referral Hospital, Uganda.

\section{Methods}

\section{Study design and setting}

We conducted a cross-sectional study at Mbarara Regional Referral Hospital, which is an urban public teaching hospital, with a 600-bed capacity, offering general and specialized health services. It is located in Mbarara city $271 \mathrm{KM}$ from Kampala the capital city, serves a population of approximately 4 million people and is a referral Centre for nine districts, in South Western Uganda.

\section{Study population, inclusion and exclusion criteria}

Women attending a post-natal clinic at Mbarara Regional Referral Hospital, who were at most six weeks post-partum, and consented to participate in the study, were enrolled between May and August 2016. 
Women who were critically ill, or had major complications that precluded study participation were excluded.

\section{Study sampling and data collection}

We used simple random sampling to enroll 385 women who were attending the postnatal clinic. A structured pretested interviewer administered questionnaire was used to collect data, after obtaining informed consent.

\section{Study variables}

Dependent variable was herbal medicine use during the most recent pregnancy, and was collected as a binary variable.

Independent variables were categorized under social demographic, socio-behavioral and health system factors.

Socio-demographic factors included age, religion, occupation, marital status, level of education and parity. They were all analyzed as categorical variables.

Socio-behavioral factors included; knowledge about herbal medicine, perception that herbal medicine is important and perception that herbal medicine is safe; were analyzed as binary variables. Participants answered yes or no to having knowledge about herbal medicine.

Health system factors included; ANC (Antenatal care) attendance and satisfaction with ANC services, both analyzed as binary variables, while distance of participant's home from health facility and number of ANC visits were analyzed as categorical variables.

\section{Data analysis}

Data was analyzed in STATA version 14 (Texas, USA), and results presented in tables and figures. Prevalence was calculated as a proportion of enrolled women who used herbal medicines during the most recent pregnancy.

Data was analyzed at three levels. At univariate analysis, categorical/binary variables were presented as proportions. While at unadjusted analysis, the chi square test was used to determine the association between independent variables and the dependent variable. The significant factors (P-value $<0.05)$ at unadjusted were run in multivariate logistic regression. Adjusted odds ratios (aOR), 95\% confidence intervals $(\mathrm{Cl})$ and $\mathrm{P}$ values are presented in tables. A P-value $<0.05$ was considered statistically significant.

\section{Results}

\section{Participant characteristics}


A total of 385 participants were enrolled in the study, of these 132 (34.3\%) were aged 21-25 years; 154 (40.0\%) were of Anglican faith and 159 (41.3\%) were unemployed. Majority of the participants were married $315(81.8 \%)$ and $139(36.1 \%)$ had secondary education. Majority of participants had had more than one pregnancy 275 (71.4\%). Most of the participants admitted having knowledge about herbal medicine 350 (90.9\%), of these $70.9 \%$ perceived herbal medicines as safe and $71.7 \%$ perceived them as important.. One hundred forty nine (38.7\%) participants stayed more than 10 kilometers (KM) away from the health facility. Most of them had attended Antenatal care 360 (93.5\%) at least once during the recent pregnancy, of whom 107 (29.7\%) were not satisfied with the services received at heath facility. (Table 1) 
Table 1

Descriptive characteristics of study participants.

\section{Socio-Demographics}

Age

$15-20$

$21-25$

$26-30$

$>30$

Religion

Catholic

Moslem

Anglican

Others

Occupation

Unemployed

Self-employed

Formal employment

Marital status

Single

Married

\section{Education}

None

Primary

Secondary

Post-secondary

\section{Parity}

1

$>1$
Frequency $(n=385)$

Percentage (\%)

18.7

34.3

31.7

15.3

59

30.9

93

24.2

154

40.0

19

4.9

159

41.3

139

36.1

87

22.6

70

18.2

315

81.8

48

12.5

97

25.2

139

36.1

101

26.2

110

28.6

275

71.4

*the $n=350$ which corresponds with number of participants who admitted to have knowledge about herbal medicine. 


\begin{tabular}{|c|c|c|}
\hline Socio-Demographics & Frequency $(n=385)$ & Percentage (\%) \\
\hline \multicolumn{3}{|l|}{ Used Herbal Medicine } \\
\hline Yes & 271 & 70.4 \\
\hline No & 114 & 29.6 \\
\hline \multicolumn{3}{|c|}{ Disclosed herbal medicine use to Healthcare worker } \\
\hline Yes & 31 & 11.4 \\
\hline No & 240 & 88.6 \\
\hline \multicolumn{3}{|c|}{ Socio-behavioural factors } \\
\hline \multicolumn{3}{|c|}{ Knowledge about herbal medicine } \\
\hline Yes & 350 & 90.9 \\
\hline No & 35 & 9.1 \\
\hline \multicolumn{3}{|c|}{ Perception that Herbal medicines are important } \\
\hline Yes & $251^{\star}$ & 71.7 \\
\hline No & $99 *$ & 28.3 \\
\hline \multicolumn{3}{|c|}{ Perception that herbal medicines are safe } \\
\hline Yes & $248 *$ & 70.9 \\
\hline No & $102^{\star}$ & 29.1 \\
\hline \multicolumn{3}{|l|}{ Health system factors } \\
\hline \multicolumn{3}{|c|}{ Distance of participant's home from the health facility } \\
\hline$</=10 \mathrm{KM}$ & 236 & 61.3 \\
\hline$>10 \mathrm{KM}$ & 149 & 38.7 \\
\hline \multicolumn{3}{|c|}{ Attended ANC at least once } \\
\hline Yes & 360 & 93.5 \\
\hline No & 25 & 6.5 \\
\hline \multicolumn{3}{|l|}{ Number of ANC visits } \\
\hline$<4$ & 220 & 61.1 \\
\hline$>/=4$ & $140^{\$}$ & 38.9 \\
\hline
\end{tabular}

*the $n=350$ which corresponds with number of participants who admitted to have knowledge about herbal medicine. 


\begin{tabular}{|lcc|}
\hline Socio-Demographics & Frequency $(\mathbf{n = 3 8 5 )}$ & Percentage $(\%)$ \\
\hline Satisfaction with ANC services & & 70.3 \\
\hline Yes & $253^{\$}$ & 29.7 \\
\hline No & $107^{\$}$ & \\
\hline $\begin{array}{l}* t h e \\
\text { herbal medicine. }\end{array}$ & & \\
\hline
\end{tabular}

$\$ n=360$, which corresponds with number of participants who attended Antenatal Care (ANC)

\section{Prevalence of herbal medicine use in pregnancy}

The prevalence of herbal medicine use in pregnancy was 70.4\% (271) (See Table 1). Of 271 who used herbal medicine in pregnancy, $43.5 \%$ used them during the first trimester, while $76.4 \%$ used them during labor (Fig. 1). Most of the participants 240 (88.6\%) reported that they did not disclose herbal medicine use to their attending HealthCare Worker.

\section{Adjusted logistic regression model for herbal medicine use in pregnancy}

At the adjusted analysis, the perception that herbal medicines are safe (aOR 9.8, 95\% $\mathrm{Cl}(4.2-23.0)$, perception that herbal medicines are important (aOR 12.4, 95\% $\mathrm{Cl}$ (5.2-29.5), staying more than $10 \mathrm{KM}$ from the heath facility (aOR 3.1, 95\% Cl (1.4-6.9), being a first time mother (aOR 2.6, 95\% $\mathrm{Cl}(1.1-6.2)$ and dissatisfaction with ANC services at health facility (aOR 2.6,95\% Cl (1.1-6.3), were associated with herbal medicine use in pregnancy as shown in Table 2 
Table 2

Adjusted and Unadjusted logistic regression of the factors associated with herbal medicine (HM) use in pregnancy

\begin{tabular}{|c|c|c|c|c|c|c|}
\hline \multirow[t]{2}{*}{ Variable } & \multirow{2}{*}{$\begin{array}{l}\text { Used HM (n } \\
=271)(\mathrm{Col} \\
\%)\end{array}$} & \multirow{2}{*}{$\begin{array}{l}\text { No HM Use } \\
(n=114)(\mathrm{Col} \\
\%)\end{array}$} & \multicolumn{2}{|l|}{$\begin{array}{l}\text { Unadjusted } \\
\text { analysis }\end{array}$} & \multicolumn{2}{|c|}{ Adjusted analysis } \\
\hline & & & $\begin{array}{l}\text { COR 95\% } \\
\text { (Cl) }\end{array}$ & $\begin{array}{l}P \\
\text { value }\end{array}$ & $\begin{array}{l}\text { aOR 95\% } \\
\text { (Cl) }\end{array}$ & $\begin{array}{l}P \\
\text { value }\end{array}$ \\
\hline \multicolumn{7}{|c|}{$\begin{array}{l}\text { Social Demographics } \\
\text { Factors }\end{array}$} \\
\hline \multicolumn{7}{|l|}{ Age } \\
\hline $15-20$ & $46(17)$ & $26(22.8)$ & & & & \\
\hline $21-25$ & $91(33.6)$ & $41(36)$ & $\begin{array}{l}1.3(0.7- \\
2.3)\end{array}$ & 0.46 & & \\
\hline $26-30$ & $93(34.4)$ & $29(25.4)$ & $\begin{array}{l}1.8(1.0- \\
3.4)\end{array}$ & 0.07 & & \\
\hline$>30$ & $41(15)$ & 18(15.8) & $\begin{array}{l}1.3(0.6- \\
2.7)\end{array}$ & 0.50 & & \\
\hline \multicolumn{7}{|l|}{ Religion } \\
\hline Catholic & $91(33.6)$ & $28(24.6)$ & $\begin{array}{l}2.4(0.9- \\
6.5)\end{array}$ & 0.93 & & \\
\hline Moslem & $63(23.3)$ & $30(26.3)$ & $\begin{array}{l}1.5(0.6- \\
4.2)\end{array}$ & 0.41 & & \\
\hline Anglican & 106(39.1) & $48(42.1)$ & $\begin{array}{l}1.6(0.6- \\
4.3)\end{array}$ & 0.34 & & \\
\hline Others & $11(4.1)$ & $8(7.0)$ & & & & \\
\hline
\end{tabular}

$*_{n}=267$ which corresponds with number of participants who admitted to have knowledge about herbal medicine and used herbal medicine.

${ }^{*} \mathrm{n}=83$ which corresponds with number of participants who admitted to have knowledge about herbal medicine and didn't use herbal medicine.

$\$ n=248$ which corresponds with number of participants who attended Antenatal Care (ANC) and used herbal medicine.

$\$ \$ n=112$ which corresponds with number of participants who attended Antenatal Care (ANC) and didn't use herbal medicine.

OR-Odds Ratios Cl- 95\% Confidence interval ANC-Antenatal care 


\begin{tabular}{|c|c|c|c|c|c|c|}
\hline \multirow{2}{*}{$\begin{array}{l}\text { Variable } \\
\text { Unemployed }\end{array}$} & \multirow{2}{*}{$\begin{array}{l}\text { Used HM (n } \\
=271)(\mathrm{Col} \\
\%) \\
122(45)\end{array}$} & \multirow{2}{*}{ 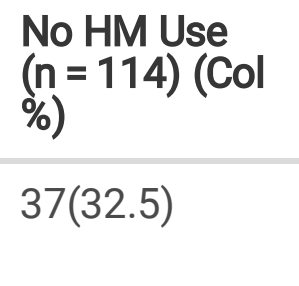 } & \multicolumn{2}{|l|}{$\begin{array}{l}\text { Unadjusted } \\
\text { analysis }\end{array}$} & \multicolumn{2}{|c|}{ Adjusted analysis } \\
\hline & & & $\begin{array}{l}2.2(1.3- \\
3.9)\end{array}$ & 0.01 & $\begin{array}{l}0.7(0.2- \\
2.4)\end{array}$ & 0.59 \\
\hline self-employed & $97(35.8)$ & $42(36.8)$ & $\begin{array}{l}1.6(0.9- \\
2.7)\end{array}$ & 0.12 & $\begin{array}{l}0.4(0.1- \\
1.0)\end{array}$ & 0.06 \\
\hline formal employment & $52(19.2)$ & $35(30.7)$ & & & & \\
\hline \multicolumn{7}{|l|}{ Marital status } \\
\hline Single & $48(17.7)$ & 22(19.3) & & & & \\
\hline Married & $223(82.3)$ & $92(80.7)$ & $\begin{array}{l}1.1(0.6- \\
2.0)\end{array}$ & 0.71 & & \\
\hline \multicolumn{7}{|l|}{ Education } \\
\hline None & $33(12.2)$ & 15(13.2) & $\begin{array}{l}1.6(0.8- \\
3.4)\end{array}$ & 0.19 & $\begin{array}{l}0.5(0.1- \\
2.2)\end{array}$ & 0.4 \\
\hline Primary & $81(29.9)$ & $16(14.0)$ & $\begin{array}{l}3.8(1.9- \\
7.3)\end{array}$ & $<0.01$ & $\begin{array}{l}2.2(0.7- \\
6.9)\end{array}$ & 0.19 \\
\hline Secondary & $99(36.5)$ & $40(35.1)$ & $\begin{array}{l}1.8(1.1- \\
3.2)\end{array}$ & 0.03 & $\begin{array}{l}2.2(0.8- \\
5.6)\end{array}$ & 0.11 \\
\hline Post-secondary & $58(21.4)$ & 43(37.7) & & & & \\
\hline \multicolumn{7}{|l|}{ Parity } \\
\hline 1 & $59(21.8)$ & $51(44.7)$ & $\begin{array}{l}0.3(0.2- \\
0.6)\end{array}$ & $<.01$ & $\begin{array}{l}2.6(1.1- \\
6.2)\end{array}$ & 0.04 \\
\hline$>1$ & 212(78.2) & $63(55.3)$ & & & & \\
\hline \multicolumn{7}{|c|}{ Socio-behavioural factors } \\
\hline \multicolumn{7}{|c|}{$\begin{array}{l}\text { knowledge about herbal } \\
\text { medicine }\end{array}$} \\
\hline \multicolumn{7}{|c|}{$\begin{array}{l}{ }^{*}=267 \text { which corresponds with number of participants who admitted to have knowledge about } \\
\text { herbal medicine and used herbal medicine. }\end{array}$} \\
\hline \multicolumn{7}{|c|}{$\begin{array}{l}\star_{n}=83 \text { which corresponds with number of participants who admitted to have knowledge about } \\
\text { herbal medicine and didn't use herbal medicine. }\end{array}$} \\
\hline \multicolumn{7}{|c|}{$\begin{array}{l}\$ n=248 \text { which corresponds with number of participants who attended Antenatal Care (ANC) and } \\
\text { used herbal medicine. }\end{array}$} \\
\hline \multicolumn{7}{|c|}{$\begin{array}{l}\$ \$ n=112 \text { which corresponds with number of participants who attended Antenatal Care (ANC) and } \\
\text { didn't use herbal medicine. }\end{array}$} \\
\hline OR-Odds Ratios Cl- 9 & nfidence inter & I ANC-Antenatal & care & & & \\
\hline
\end{tabular}




\begin{tabular}{|c|c|c|c|c|c|c|}
\hline Variable & $\begin{array}{l}\text { Used HM (n } \\
=271)(\mathrm{Col} \\
\%)\end{array}$ & $\begin{array}{l}\text { No HM Use } \\
(n=114)(\mathrm{Col} \\
\%)\end{array}$ & $\begin{array}{l}\text { Unadjusted } \\
\text { analysis }\end{array}$ & & \multicolumn{2}{|c|}{ Adjusted analysis } \\
\hline Yes & $267(98.5)$ & $83(72.8)$ & $\begin{array}{l}24.9(8.6- \\
33.6)\end{array}$ & \multicolumn{3}{|l|}{$<0.01$} \\
\hline No & $4(1.5)$ & $31(27.2)$ & & & & \\
\hline \multicolumn{7}{|c|}{$\begin{array}{l}\text { Perception that Herbal } \\
\text { medicines are } \\
\text { important }\end{array}$} \\
\hline Yes & $230(86.1)^{\star}$ & $21(25.3)^{\star \star \star}$ & $\begin{array}{l}\text { 18.4(10.0- } \\
33.6)\end{array}$ & $\begin{array}{l}< \\
0.01\end{array}$ & $\begin{array}{l}12.4(5.2- \\
29.5)\end{array}$ & $\begin{array}{l}< \\
0.01\end{array}$ \\
\hline No & $37(13.9) *$ & $62(74.7)^{\star \star}$ & & & & \\
\hline \multicolumn{7}{|c|}{$\begin{array}{l}\text { Perception that herbal } \\
\text { medicines are safe }\end{array}$} \\
\hline Yes & $228(85.4)^{*}$ & $20(24.1)^{\star \star}$ & $\begin{array}{l}18.4(10.0- \\
33.8)\end{array}$ & $\begin{array}{l}< \\
0.01\end{array}$ & $\begin{array}{l}9.8(4.2- \\
23.0)\end{array}$ & $\begin{array}{l}< \\
0.01\end{array}$ \\
\hline No & $39(14.6)^{\star}$ & $63(75.9)^{\star \star}$ & & & & \\
\hline \multicolumn{7}{|c|}{ Health system factors } \\
\hline \multicolumn{7}{|c|}{$\begin{array}{l}\text { Distance of } \\
\text { participant's home from } \\
\text { the health facility }\end{array}$} \\
\hline$</=10 \mathrm{KM}$ & 157(57.9) & $79(69.3)$ & & & & \\
\hline$>10 \mathrm{KM}$ & $114(42.1)$ & $35(30.7)$ & $\begin{array}{l}1.6(1.0- \\
2.6)\end{array}$ & 0.04 & $\begin{array}{l}3.1(1.4- \\
6.9)\end{array}$ & 0.01 \\
\hline \multicolumn{7}{|c|}{ Attended ANC at least once } \\
\hline Yes & $248(91.5)$ & 112(98.3) & & & & \\
\hline No & $23(8.5)$ & $2(1.7)$ & $\begin{array}{l}5.2(1.2- \\
22.4)\end{array}$ & 0.03 & & \\
\hline \multicolumn{7}{|c|}{$\begin{array}{l}*_{n}=267 \text { which corresponds with number of participants who admitted to have knowledge about } \\
\text { herbal medicine and used herbal medicine. }\end{array}$} \\
\hline \multicolumn{7}{|c|}{$\begin{array}{l}\star \star n=83 \text { which corresponds with number of participants who admitted to have knowledge about } \\
\text { herbal medicine and didn't use herbal medicine. }\end{array}$} \\
\hline \multicolumn{7}{|c|}{$\begin{array}{l}\$ n=248 \text { which corresponds with number of participants who attended Antenatal Care (ANC) and } \\
\text { used herbal medicine. }\end{array}$} \\
\hline \multicolumn{7}{|c|}{$\begin{array}{l}\$ \$ n=112 \text { which corresponds with number of participants who attended Antenatal Care (ANC) and } \\
\text { didn't use herbal medicine. }\end{array}$} \\
\hline \multicolumn{7}{|c|}{ OR-Odds Ratios Cl- 95\% Confidence interval ANC-Antenatal care } \\
\hline
\end{tabular}




\begin{tabular}{|c|c|c|c|c|c|c|}
\hline Variable & $\begin{array}{l}\text { Used HM (n } \\
=271)(\mathrm{Col} \\
\%)\end{array}$ & $\begin{array}{l}\text { No HM Use } \\
(n=114)(\text { Col } \\
\%)\end{array}$ & $\begin{array}{l}\text { Unadjusted } \\
\text { analysis }\end{array}$ & & \multicolumn{2}{|c|}{ Adjusted analysis } \\
\hline \multicolumn{7}{|c|}{ Number of ANC visits } \\
\hline$<4$ & $157(63.3)^{\$}$ & $63(56.3) \$ \$$ & $\begin{array}{l}1.3(0.9- \\
2.1)\end{array}$ & 0.2 & & \\
\hline$>/=4$ & $91(36.7) \$$ & $49(43.8) \$$ & & & & \\
\hline \multicolumn{7}{|c|}{$\begin{array}{l}\text { Satisfaction with ANC } \\
\text { services }\end{array}$} \\
\hline yes & $159(64.1)^{\$}$ & 94(83.9) & & & & \\
\hline No & $89(35.9)^{\$}$ & 18(16.1) & $\begin{array}{l}2.9(1.7- \\
5.2)\end{array}$ & $<0.01$ & $\begin{array}{l}2.6(1.1- \\
6.3)\end{array}$ & 0.04 \\
\hline \multicolumn{7}{|c|}{$\begin{array}{l}*_{n}=267 \text { which corresponds with number of participants who admitted to have knowledge about } \\
\text { herbal medicine and used herbal medicine. }\end{array}$} \\
\hline \multicolumn{7}{|c|}{$\begin{array}{l}{ }^{\star} \mathrm{n}=83 \text { which corresponds with number of participants who admitted to have knowledge about } \\
\text { herbal medicine and didn't use herbal medicine. }\end{array}$} \\
\hline \multicolumn{7}{|c|}{$\begin{array}{l}\$ n=248 \text { which corresponds with number of participants who attended Antenatal Care (ANC) and } \\
\text { used herbal medicine. }\end{array}$} \\
\hline \multicolumn{7}{|c|}{$\begin{array}{l}\$ \$=112 \text { which corresponds with number of participants who attended Antenatal Care (ANC) and } \\
\text { didn't use herbal medicine. }\end{array}$} \\
\hline \multicolumn{7}{|c|}{ OR-Odds Ratios $\mathrm{Cl}-95 \%$ Confidence interval ANC-Antenatal care } \\
\hline
\end{tabular}

\section{Discussion}

Use of herbal medicines is common amongst pregnant women in south western Uganda.

While herbal medicine is usually perceived as a rural phenomenon (19), the prevalence of herbal medicine in this current study done in an urban setting is high. This prevalence is similar to that reported other urban settings in Sub-Saharan Africa $(12,20,21)$. However, the prevalence we report is higher than the reported prevalence in Northern Uganda(14), and other studies done in East Africa $(11,22)$ and West Africa $(10,23)$. This may be due to the difference in the social-cultural beliefs of the populations in these different study areas. Nonetheless, the study done in Nigeria by Gharoro and colleague (10) considered a few herbal medicines, which was not a representative of herbal medicine use among all pregnant women and possibly explains the lower prevalence they report.

Whereas pregnant mothers have different reasons for herbal medicine use in different stages of pregnancy, this current study revealed that more than three quarters of herbal medicine users, used them during labor. This finding is similar to what has been reported in Ethiopia(24). In addition, $80 \%$ of 
pregnant women in rural areas of western Uganda deliver using herbal remedies (13). Labor is a critical stage of pregnancy and should be handled with utmost care because it has a great impact on the health of the mother and baby, as well as pregnancy outcome. Therefore, health workers should always be keen to screen for herbal medicine use during labor process.

The findings of the current study showed that participants who perceived that herbal medicines are safe and important, were more likely to use them during pregnancy. This is consistent with the study done in Sub-Saharan Africa $(11,14,25)$. In Northern Uganda, study found out that most women regard herbal medicines as "effective and safe" in addition to treating a wide range of ailments(14). Additionally, pregnant women in Nigeria use herbal medicines because they perceive them as "natural" and "safe" with no side effects (20). This is however not backed up by evidence since there is generally paucity of studies evaluating the safety and efficacy of these herbal preparations in Africa. Further still, the dosage profiles of these herbs are largely unknown. Our findings also show that majority of women attended antenatal care from a health facility at least once an indication that they believe and use conventional therapies and herbal medicines concurrently, further causing worry for potential drug-herb interactions. Therefore, health workers should be keen to assess herbal medicine use during routine ANC visits and educate pregnant women about the potential consequences of these herbal medicines.

In this current study, we show that first time mothers were more likely to use herbal medicines compared to those who had more than one pregnancy, which is consistent with other studies (26-28). This may be attributed to naivety to the pregnancy experience, which makes them vulnerable to take any herbal medicines recommended to them by their parents and relatives(28). The various pregnancy related ailments that are new to first time mothers may also trigger them to use herbal medicine.

We show that respondents who lived further from the health facility were more likely to use herbal medicine and is consistent with findings from elsewhere in East Africa(28). In the context of health care generally, long distances have also been associated with poor uptake of services among pregnant mothers $(14,29)$. This is so critical in a sense that pregnant women will find it so easy to use the herbal medicines which are accessible compared to the conventional care. Furthermore, it is documented that over $80 \%$ of pregnant women in Western Uganda deliver at their homes mainly with the assistance of traditional birth attendants who use herbal medicines (13). Therefore in the effort to improve maternal health and check on the stagnantly high maternal mortality, government should decentralize maternal health services, to increase accessibility to the population.

In this current study, we demonstrate that respondents, who were not satisfied with the services rendered to them at the health facility, were more likely to use herbal medicines during their most recent pregnancy. This finding is comparable with a study done in northern Uganda(14). Additionally, a systematic review of literature in developing countries revealed that a wide range of structural, process and outcome factors influence women's satisfaction, and ultimately their update of conventional therapies, which leaves them with an option of using herbal medicines which are less costly and readily available(30). It's therefore 
important that maternal health programs in health facilities put into account women's perspective of care they need in order to improve services delivered.

Majority of pregnant women who used herbal medicines did not disclose to the attending health care workers (HCW). This finding is consistent with the previous studies in sub Saharan Africa $(11,14,25,31$, 32). The qualitative study done in rural Ghana also confirm that much as pregnant women use both conventional and herbal medicines, they were hesitant to disclose herbal medicine use to their attending HCW for several reasons such as; the belief that herbs are "natural and safe", fear of losing control of their health, perception that HCW don't have knowledge about herbs and fear of being victimized or discouraged by HCW(32). This therefore calls for health workers' concerted effort to continually update themselves on the herbs commonly used in their local communities. It is also relevant that HCWs actively assess herbal medicine use when pregnant women come to the health facilities during antenatal care or labor.

\section{Limitations and Strengths}

The data about pregnancy experiences was collected retrospectively, which makes it prone to recall bias. This was however reduced by considering women who were only six weeks postpartum and below. Furthermore, women with severe complications like uncociousness were excluded from participation, and therefore we couldn't determine associations between herbal medicine and complications, or if developing complications led to the use of herbal medicine.

The study was conducted in a hospital setting and therefore, it is likely that some participants may have concealed information due to fear of perceived repercussions regarding care or stigma. This was reduced by explaining to the participants that this was an independent survey which would not in any way affect the quality of care being received in the hospital. In addition, using the hospital setting as our sampling frame could have introduced selection bias therefore the herbal medicine use we report may not be representative of the region.

Despite these limitations, our findings highlight an important area that the health care system should study further in collaboration with herbalists.

\section{Conclusion}

The use of herbal medicine is common among pregnant women in the study area. Most pregnant women seek conventional therapies but also use herbal medicines concurrently. This calls for community sensitization drives to change the perception of women regarding use of these herbal medicines in pregnancy. HCWs should always assess for the use of herbal medicines during antenatal care and advise pregnant women to make informed decisions.

\section{Abbreviations}


ANC: Antenatal Care

aOR: Adjusted Odds Ratio

COR: Crude Odds Ratio

Cl: Confidence Interval

HCW: Healthcare Worker

HM: Herbal medicine

HMIS: Health Management Information systems

KM: Kilometer

USA: United States of America

WHO: World Health Organization

\section{Declarations}

\section{Ethical Approval and Consent to participate}

The research study was reviewed and approved by the departments of Obstetrics and Gynecology and Administration of Mbarara Regional Referral hospital.

Written informed consent was obtained from each participant before study procedure. Assent from minor participants (below 18years) and informed consent from their parents or legal guardians was obtained before study procedures. All methods were conducted in accordance with good clinical practice and regulatory requirements of Uganda National Council of Science and Technology.

\section{Consent to publication}

Not applicable

\section{Availability of data and materials}

All data analyzed during this study are included in this publication (attached as supplementary information file)

\section{Competing interests}

Authors declare no competing interests

\section{Funding}


The authors received no specific funding for this work.

\section{Authors' contributions}

LM (corresponding Author) participated in the initial conception of the study, design, data collection, analysis interpretation and drafting of the final version of the manuscript.

AS participated in the analysis, interpretation, and review the manuscript

AN participated in the analysis, interpretation, and review the manuscript

DM participated in the study design data collection, analysis, interpretation and drafting the manuscript

YM participated in the analysis, interpretation, drafting and extensive review of the manuscript

All authors listed above, approved the final manuscript for submission and consent to publish it.

\section{Acknowledgements}

Deep appreciation goes to Dr. Breanda Oketch Dr. Julient Mpendo, Talbert Muhwezi and Dr. Umar Hassan for their generous support and mentorship.

\section{References}

1. Bayisa B, Tatiparthi R, Mulisa E. Use of herbal medicine among pregnant women on antenatal care at nekemte hospital, Western ethiopia. Jundishapur J Nat Pharm Prod. 2014 Nov;9(4):e17368.

2. Nikolajsen T, Nielsen F, Rasch V, Sorensen PH, Ismail F, Kristiansen U, et al. Uterine contraction induced by Tanzanian plants used to induce abortion. J Ethnopharmacol. 2011 Sep;137(1):921-5.

3. Geneva WHO. World Health Organization General Guidelines for Methodologies on Research and Evaluation of Traditional Medicine. WHO Geneva. 2000;

4. (WHO) WHO. WHO Traditional Medicine Strategy 2002-2005. Geneva: World Health Organization. 2002.

5. Tabatabaee M. Use of herbal medicine among pregnant women referring to Valiasr Hospital in Kazeroon, Fars, South of Iran. J Med Plants. 2011 Mar 1;10:96-108.

6. Nordeng H, Havnen GC. Use of herbal drugs in pregnancy: a survey among 400 Norwegian women. Pharmacoepidemiol Drug Saf. 2004 Jun;13(6):371-80.

7. James PB, Wardle J, Steel A, Adams J. Traditional, complementary and alternative medicine use in Sub-Saharan Africa: a systematic review. BMJ Glob Heal. 2018;3(5):e000895.

8. Dugoua J-J. Herbal medicines and pregnancy. J Popul Ther Clin Pharmacol $=\mathrm{J}$ la Ther des Popul la Pharmacol Clin. 2010;17(3):e370-8.

9. John LJ, Shantakumari N. Herbal Medicines Use During Pregnancy: A Review from the Middle East. Oman Med J. 2015 Jul;30(4):229-36. 
10. Gharoro EP, Igbafe AA. Pattern of drug use amongst antenatal patients in Benin City, Nigeria. Med Sci Monit. 2000;6(1):84-7.

11. Mothupi MC. Use of herbal medicine during pregnancy among women with access to public healthcare in Nairobi, Kenya: a cross-sectional survey. BMC Complement Altern Med [Internet]. 2014 Dec 4;14(1):432. Available from: https://bmccomplementalternmed.biomedcentral.com/articles/10.1186/1472-6882-14-432

12. Addo V. "Herbal Medicines: Socio-Demographic Characteristics And Pattern Of Use By Patients In A Tertiary Obstetrics And Gynaecology Unit." J Sci Technol. 2008;Vol.27(No.3, 2007):PP149-155.

13. Kamatenesi-Mugisha $M$, Oryem-Origa $\mathrm{H}$. Medicinal plants used to induce labour during childbirth in western Uganda. J Ethnopharmacol. 2007 Jan;109(1):1-9.

14. Nyeko R, Tumwesigye NM, Halage AA. Prevalence and factors associated with use of herbal medicines during pregnancy among women attending postnatal clinics in Gulu district, Northern Uganda. BMC Pregnancy Childbirth. 2016 Oct;16(1):296.

15. (Uganda) M of health. "Why did they die?" Reviewing the evidence to save tomorrow's mothers and babies [Internet]. 2014. Available from: http://publications.universalhealth2030.org/uploads/mpdrreport-2012-13-final-version-06-01-2014.pdf Accessed May 2020

16. Nelson JP. Posterior uterine rupture secondary to use of herbs leading to peritonitis and maternal death in a primigravida following vaginal delivery of a live baby in western Uganda: a case report. Pan Afr Med J. 2016;23:81.

17. Mukasa PK, Kabakyenga J, Senkungu JK, Ngonzi J, Kyalimpa M, Roosmalen VJ. Uterine rupture in a teaching hospital in Mbarara, western Uganda, unmatched case- control study. Reprod Health. 2013 May;10:29.

18. Vickers KA, Jolly KB, Greenfield SM. Herbal medicine: women's views, knowledge and interaction with doctors: a qualitative study. BMC Complement Altern Med. 2006 Dec;6:40.

19. Njoroge GN, Kibunga JW. Herbal medicine acceptance, sources and utilization for diarrhoea management in a cosmopolitan urban area (Thika, Kenya). Afr J Ecol. 2007;45:65-70.

20. Fakeye TO, Adisa R, Musa IE. Attitude and use of herbal medicines among pregnant women in Nigeria. BMC Complement Altern Med [Internet]. 2009;9(1):53. Available from: https://doi.org/10.1186/1472-6882-9-53

21. Tamuno I, Omole-Ohonsi A, Fadare J. Use Of Herbal Medicine Among Pregnant Women Attending A Tertiary Hospital In Northern Nigeria. Internet J Gynecol Obstet. 2011 Jan 1;15.

22. Nordeng H, Havnen G. Impact of socio-demographic factors, knowledge and attitude on the use of herbal drugs in pregnancy. Acta Obstet Gynecol Scand. 2005 Feb 1;84:26-33.

23. Duru CB, Uwakwe KA, Chinomnso NC, Mbachi II, Diwe KC, Agunwa CC, et al. Socio-demographic determinants of herbal medicine use in pregnancy among nigerian women attending clinics in a tertiary hospital in Imo State, South-East, Nigeria. Am J Med Stud. 2016;4(1):1-10.

24. Mekuria AB, Erku DA, Gebresillassie BM, Birru EM, Tizazu B, Ahmedin A. Prevalence and associated factors of herbal medicine use among pregnant women on antenatal care follow-up at University of 
Gondar referral and teaching hospital, Ethiopia: a cross-sectional study. BMC Complement Altern Med. 2017 Feb;17(1):86.

25. James PB, Bah AJ, Tommy MS, Wardle J, Steel A. Herbal medicines use during pregnancy in Sierra Leone: An exploratory cross-sectional study. Women and Birth. 2018;31(5):e302-9.

26. Ab Rahman A, Ahmad Z, Naing L, Sulaiman SA, Hamid AM, Daud WN, et al. The use of herbal medicines during pregnancy and perinatal mortality in Tumpat District, Kelantan, Malaysia. Southeast Asian J Trop Med Public Heal. 2007;38(6):1150-7.

27. Odalovic M, Kovacevic SV, Nordeng H, llic K, Sabo A, Tasic L. Predictors of the use of medications before and during pregnancy. Int J Clin Pharm. 2013;35(3):408-16.

28. Godlove MJ. Prevalence of herbal medicine use and associated factors among pregnant women attending antenatal clinic at Mbeya Refferal Hospital in 2010. Muhimbili University of Health and Allied Sciences; 2011.

29. Mpembeni RNM, Killewo JZ, Leshabari MT, Massawe SN, Jahn A, Mushi D, et al. Use pattern of maternal health services and determinants of skilled care during delivery in Southern Tanzania: implications for achievement of MDG-5 targets. BMC Pregnancy Childbirth. 2007;7(1):1-7.

30. Srivastava A, Avan BI, Rajbangshi P, Bhattacharyya S. Determinants of women's satisfaction with maternal health care: a review of literature from developing countries. BMC Pregnancy Childbirth. 2015;15(1):97.

31. Mothupi MC. Use of herbal medicine during pregnancy among women with access to public healthcare in Nairobi , Kenya: a cross-sectional survey. 2014;1-8.

32. Peprah P, Agyemang-Duah W, Arthur-Holmes F, Budu HI, Abalo EM, Okwei R, et al. "We are nothing without herbs": a story of herbal remedies use during pregnancy in rural Ghana. BMC Complement Altern Med. 2019 Mar;19(1):65.

\section{Figures}




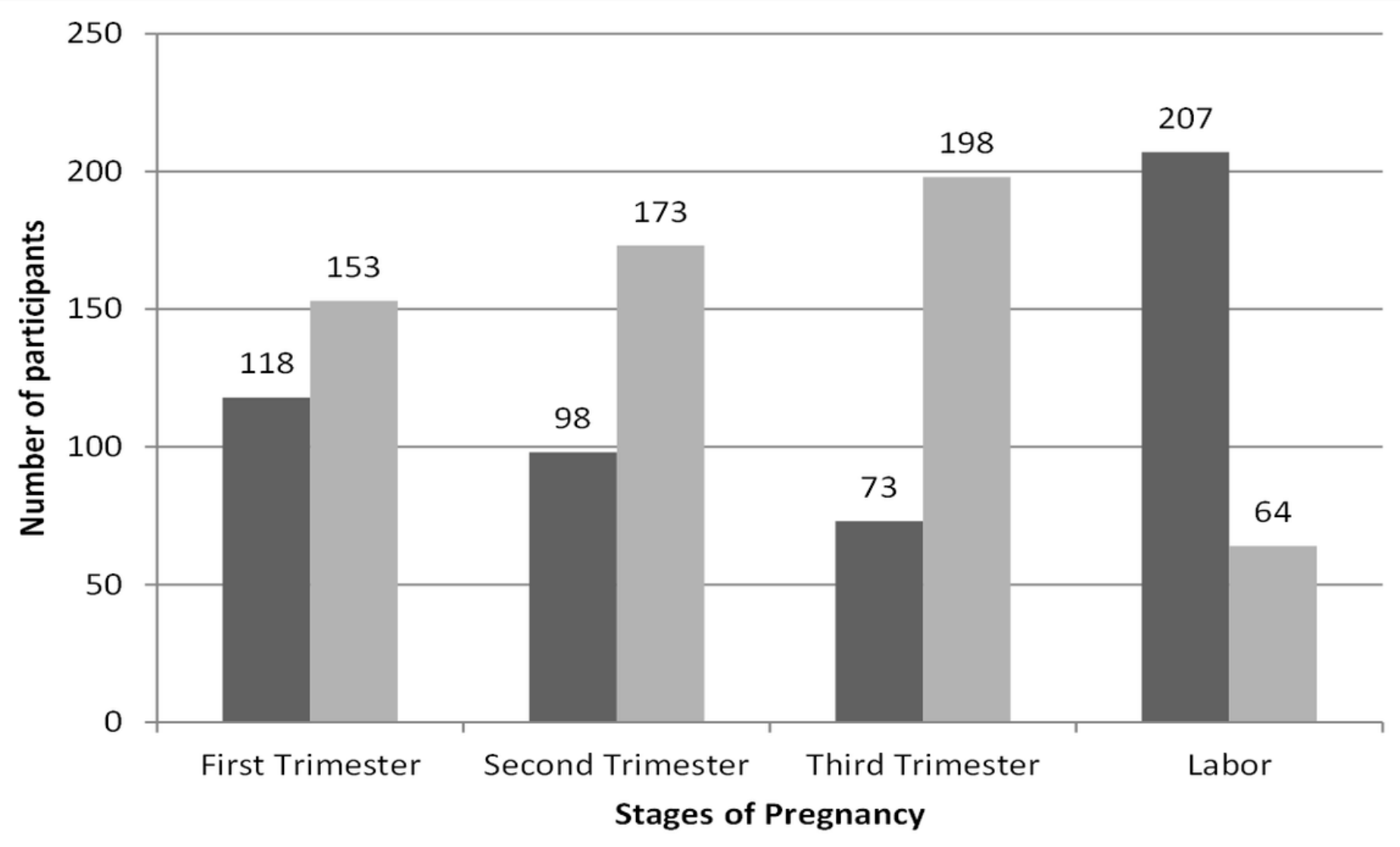

a Used Herbal Medicine $\quad$ Never Used Herbal Medicine

\section{Figure 1}

Herbal medicine use by pregnant women in the stages of pregnancy.

\section{Supplementary Files}

This is a list of supplementary files associated with this preprint. Click to download.

- Additionalfile1dataset.dta

- Additionalfile2descriptionofdata.pdf 